\title{
APLIKASI PENGENALAN LAGU ANAK-ANAK BERBASIS ANDROID
}

\author{
Aris H. Rismayana ${ }^{1)}$,Putri Kartika Dewi ${ }^{2)}$ \\ 1),2)Teknik Komputer, Politeknik TEDC Bandung \\ E-mail: rismayana@gmail.com ${ }^{1)}$ _putrikartikadewi189@gmail.com ${ }^{2)}$
}

\begin{abstract}
Abstrak
Lagu anak yang menggunakan bahasa Indonesia selain dapat digunakan sebagai media belajar bahasa, juga memiliki nilai pendidikan dan dapat membentuk karakter positif terutama pada lirik-liriknya yang menggunakan kata-kata positif. Namun pada tahun 2015 lagu anak-anak seakan hilang, media elektronik lebih sering memutar dan menayangkan lagu dewasa yang bertemakan percintaan mengakibatkan anakanak menyukai lagu yang tidak sesuai dengan usia anak-anak. Tujuan yang hendak dicapai oleh penulis adalah mengembangkan sebuah aplikasi yang dapat memudahkan anak-anak dalam mempelajari dan menghafal lagu anak-anak yang dapat berjalan pada telepon seluler dengan sistem operasi Android.
\end{abstract}

Kata kunci: lagu anak-anak, unsur musik, android

\begin{abstract}
Children songs who use the Indonesian language besides can be used as a medium of learning language, also has the value of education and could building a positive character, especially in the lyrics that use positive words. But by 2015 children's songs seem to disappear, electronic media more often play and show adult songs with the theme of love resulted in children like songs that do not fit with the age of children. The goal of the research is to develop an application that can make it easier for children to learn and memorize the songs of children who can run on mobile phones with the Android operating system.
\end{abstract}

Keyword: children songs, music elements, android

\section{PENDAHULUAN}

Pada tahun 2015 anak-anak lebih menyukai lagu-lagu bertemakan dewasa, daripada lagu yang sesuai dengan usia anak-anak. Kegemaran anak-anak yang cenderung lebih menyukai lagulagu dewasa menjadi kekhawatiran bagi orang tua. Beberapa faktor yang menyebabkan langkanya lagu anak saat ini :

1. Media TV dan Radio jarang memuat acara untuk anak-anak dan lebih banyak menyiarkan lagu dewasa, membuat anakanak merubah kegemaran pada lagu dewasa.

2. Saat ini lagu anak dalam bentuk $C D$ atau kaset hanyalah hasil dari daur ulang lagulagu anak lawas. Hal ini tentu membuat anak-anak semakin bosan, dan kurang menggemari lagu anak yang terkesan kuno. Meskipun beberapa album lagu anak telah terbit, namun jarang yang terekspos media.

3. Penjual $C D$ lebih banyak memutarkan lagu dewasa daripada lagu anak-anak.

Anak-anak mulai kehilangan Idola Anak. Meskipun idola anak itu ada, namun anak-anak banyak yang menyanyikan lagu-lagu dewasa. Hal ini tentu membawa pengaruh buruk pada dunia musik anak (Budhianto, 2014).
Tidak hanya lagu, anak-anak juga lebih menyukai bermain permainan yang terdapat dalam gadget. Dilihat dari tahapan perkembangan dan usia anak, pengenalan dan penggunaan gagdet bisa dibagi ke beberapa tahapan usia.

Untuk usia 4-5 tahun orangtua berperan untuk tetap mendampingi dalam penggunaan gadget, orangtua menjelaskan dan membantu anak mengaitkan antara apa yang ada di gadget dengan apa yang dilihat di dunia nyata, serta membatasi waktu dalam memainkan gadget.

Untuk usia 6-10 tahun orangtua boleh memperbanyak waktu anak dalam menggunakan gadget karena anak harus menggali informasi dari lingkungan tentunya dengan batasan waktu terhadap gadget contoh dalam seminggu anak boleh menggunakan gadget hari sabtu dan minggu selama 2 jam sehingga anak mampu menggunakan gadget secara bertanggungjawab dan tidak kecanduan (Ferliana, 2014).

Berdasarkan penjelasan di atas, penulis tertarik untuk membuat aplikasi dengan memanfaatan keberadaan gadget untuk meningkatkan daya tarik anak-anak di bidang musik yang berjudul "APLIKASI PENGENALAN LAGU ANAK-ANAK BERBASIS MOBILE". 


\section{LANDASAN TEORI Definisi Musik}

Definisi dari musik sangat beragam, diantaranya adalah musik merupakan bunyibunyian yang dapat ditangkap oleh indera pendengar. Pendapat lain menerangkan bahwa musik merupakan suatu karya seni dengan berbagai unsur pokok dan pendukungnya.

Menurut Kamus Besar Bahasa Indonesia "musik adalah ilmu atau seni penyusunan nada/suara, kombinasi, dan hubungan temporal untuk menghasilkan komposisi (suara) yg mempunyai kesatuan \& kesinambungan".

\section{Definisi Lagu}

Lagu merupakan gubahan seni nada atau suara dalam urutan, kombinasi, dan hubungan temporal (biasanya diiringi dengan alat musik) untuk menghasilkan gubahan musik yang mempunyai kesatuan dan kesinambungan (mengandung irama). Dan ragam nada atau suara yang berirama disebut juga dengan lagu.

\section{Definisi Anak}

Seorang laki-laki atau perempuan yang belum matang secara tindakan dan pemikiran atau belum mengalami pubertas dapat dikategorikan sebagai seorang anak. Beberapa pengertian anak dari berbagai aspek:

1. Dari aspek ekonomi : anak dikelompokan pada golongan non produktif karena anak mengalalmi transformasi financial sebagai akibat terjadinya interaksi Ingkungan keluarga yang didasarkan nilai kemanusiaan.

2. Dari aspek sosiologi : anak diartikan sebagai makhluk ciptaan Allah swt yang senantiasan berinteraksi dalam lingkungan masyrakat bangsa dan negara, makna anak dalam aspek sosial ini lebih mengarah pada perlindungan kodrati anak itu sendiri

3. Berdasarkan UUD 1945 : anak adalah seseorang yang harus memperoleh hak-hak yang kemudian hak tersebut dapat menjamin pertumbuhan dan perkembangan dengan wajar baik secara rahasia, jasmaniah, maupun sosial.

\section{Manfaat lagu anak-anak} lain :

Adapun manfaat dari lagu-lagu anak antara

1. Melatih fungsi otak

2. Mempengaruhi mood anak

3. Melatih anak berbicara

4. Melatih kemampuan mendengar

5. Bersosialisasi

6. Memberikan ketenangan pada anak

7. Belajar membaca, menulis, dan berhitung

8. Melatih kerjasama

\section{Android}

Android merupakan sebuah perangkat lunak yang lengkap, yang terdiri dari sistem operasi, middleware dan aplikasi perangkat lunak yang utama.

Sistem oparasi android mempunyai beberapa kelebihan, diantaranya :

1. Terbuka

Android memungkinkan programmer dapat membuat aplikasi mobile yang menarik dengan memanfaatkan sepenuhnya semua fitur yang terdapat pada handset. Misalnya, aplikasi dapat memanggil fitur inti ponsel seperti telepon, mengirim pesan teks, atau menggunakan kamera.

2. Semua aplikasi diciptakan sama

Android tidak membedakan antara aplikasi utama ponsel dengan aplikasi pihak ketiga. Semuanya mendapatkan akses yang sama terhadap kemampuan telepon dan semua fitur yang ada pada handset.

3. Menghilangkan batasan aplikasi

Android menghilangkan penghalang bagi programmer untuk membangun aplikasi baru dan inovatif. Misalnya, programmer dapat menggabungkan informasi dari web dengan data pada handset (kontak pengguna, kalender, atau lokasi geografis) untuk memberikan pengalaman pengguna yang lebih relevan. Dengan Android, programmer dapat membuat aplikasi yang memungkinkan pengguna melihat lokasi teman mereka.

4. Cepat dan mudah dalam pengembangan aplikasi

Android menyediakan akses ke berbagai library yang dapat digunakan untuk membangun aplikasi yang beragam. Misalnya, Android memungkinkan pengembang mendapatkan lokasi perangkat, dan memungkinkan perangkat berkomunikasi satu sama lain secara realtime.

Tidak hanya menjadi sistem operasi di smartphone, Android menjadi pesaing utama dari Apple pada sistem operasi Tablet PC. Android itu sendiri adalah platform yang sangat lengkap baik itu sistem operasinya, Aplikasi dan Tool Pengembangan, serta dukungan yang sangat tinggi dari komunitas Open Source dunia sehingga Android terus berkembang pesat (Safaat, 2013).

\section{Android Studio}

Android Studio merupakan suatu IDE yang baru dirilis oleh Google, serta telah menjadi IDE resmi untuk pembuatan aplikasi berbasis Android yang merupakan pengembangan dari Eclipse yang memiliki fitur-fitur baru dibanding Eclipse. Android Studio adalah sebuah Integrated Development Environment (IDE) untuk pengembangan aplikasi pada platform Android. Android Studio merupakan toolkit yang digunakan untuk membangun dan membuat paket aplikasi Android berdasarkan Intellij IDEA. Sama halnya dengan Eclipse, ada beberapa pilihan Aplication Building 
Tools, baik menggunakan IDE atau Command Line Interface (CLI) (Siregar, 2014).

\section{Basis Data}

Database atau basis data adalah kumpulan data-data yang disimpan di dalam komputer secara periodik dan sistematik untuk diolah sehingga mendapatkan informasi sesuai dengan yang diharapkan.

Secara umum database dibagi 2, yaitu database server dan database file.

Database server artinya database tersebut disimpan di server, disebut juga database terpusat. Database tersebut dapat diakses dimanapun secara bersama-sama secara realtime. Contoh database server diantaranya, MySQL, SQL Server, PostgreSQL, Oracle dan lain-lain.

Sedangkan database file hanya berupa file independent. Karena sifatnya yang berupa file saja, maka database tersebut tidak dapat diakses diluar komputer dimana database tersebut berada. Contoh database file antara lain MS. Access dan SQLite.

\section{Database SqLite}

SQLite adalah sebuah SQL Database Engine yang tidak membutuhkan server, tidak membutuhkan konfigurasi yang bersifat transaksional. Sebuah transaksi dalam istilah database berarti memiliki kemampuan untuk menjalankan sebuah transaksi SQL secara utuh atau atau dibatalkan sama sekali. Hal ini misalnya jika gangguan pada proses akibat crash pada mesin atau program atau yang lainya.

SQLite mendukung hampir semua fitur SQL 92. Berikut ini fitur SQL 92 yang tidak dapat diimplementasikan di SQLite.

\section{RIGHT and FULL OUTER JOIN \\ 2. Complete ALTER TABLE \\ 3. Writing to Views \\ 4. GRANK and REVOKE}

SQLite Database disimpan dalam sebuah filefile yang dapat diakses dalam berbagai sistem operasi seperti UNIX (linux, Mac OS), Windows, baik mesin 32 bit atau 64 bit. Karena kelebihan SQLite tersebut diatas, maka SQLite ini banyak digunakan dalam berbagai aplikasi, terutama aplikasi smartphone. (Yudistira, 2011)

\section{Unified Modeling Language (UML)}

UML (Unified Modeling Language) UML adalah suatu bahasa dalam rumpun Sistem Informasi yang digunakan untuk merancang, membangun dan mendokumentasikan pengembangan perangkat lunak. UML di inisiasi oleh Jim Rumbaugh, Ivar Jacobson dan Grady Booch. Dan kemudian dikembangkan sebagai suatu alat untuk analisis dan desain berorientasi objek. Namun dalam perkembangannya, UML dapat digunakan juga untuk memahami dan mendokumentasikan setiap sistem informasi.
Secara umum, terdapat 10 bagian dari UML yang bias digunakan, akan tetapi hanya beberapa bagian saja yang sering digunakan, yaitu Use Case Diagram, Activity Diagram, Sequence Diagram dan Class Diagram.

\section{PEMBAHASAN}

\section{Analisis Sistem}

Sistem aplikasi Pengenalan Lagu Anak-Anak Berbasis Mobile ini merupakan aplikasi yang mempermudah pengguna dalam mempelajari dan menghafal lagu anak-anak. Sistem aplikasi ini dapat menampilkan daftar lagu, lirik lagu dan latihan soal. Dengan menggunakan perangkat mobile android, aplikasi ini bisa diakses tanpa terhubung internet sehingga menambah kemudahan bagi pengguna.

Sebelum masuk kebagian utama dalam perancangan, dianalisis terlebih dahulu systemsistem atau aplikasi-aplikasi yang sudah ada, sebagai acuan perbandingan untuk aplikasi yang akan dibuat.

\section{Analisis Sistem Yang Sedang Berjalan}

Aplikasi Mobile Pembanding berjudul "Kumpulan Lagu Anak-Anak" karya Rizal merupakan aplikasi yang menampilkan 40 daftar lagu anak-anak, berikut kekurangan dan kelebihan pada aplikasi tersebut :

1. Kelebihan :
a. Berjalan tanpa koneksi internet
b. Mudah digunakan
c. Ringan saat dijalankan
d. Tersedia 40 lagu anak-anak

2. Kekurangan :
a. Tampilan kurang menarik
b. Hanya Menampilkan 1 Form yaitu form daftar lagu
c. Tidak ada tombol pause
d. Tidak ada lirik lagu
e. Tidak menyediakan menu latihan soal

Tampilan aplikasi "Kumpulan Lagu AnakAnak" terlihat pada gambar 1 dibawah ini :

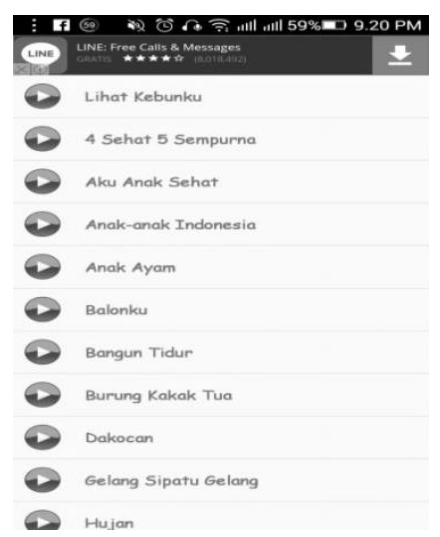

Gambar 1. Tampilan aplikasi kumpulan lagu anak-anak ketika dibuka 
Analisis Sistem Yang Akan Dibangun

Berdasarkan tinjauan terhadap beberapa aplikasi mobile yang sudah ada, maka hasil analisis dari Aplikasi Pengenalan Lagu Anak-Anak Berbasis Mobile ini adalah sebagai berikut:

a. Menu Daftar Lagu, menampilkan daftar lagu yang tersedia didalam aplikasi beserta lirik lagu tersebut.

b. Menu Kuis, menampilkan 15 latihan soal terkait lagu anak-anak sebagai bahan untuk melatih kemampuan daya ingat user dimana setelah soal selesai dijawab akan muncul form score, jika 15 soal dijawab dengan benar maka akan munucl nilai keterangan bahwa nilai sempurna.

c. Menu Tentang, menampilkan informasi mengenai aplikasi beserta biodata diri admin.

\section{Spesifikasi Target Sistem Operasi}

Aplikasi ini akan dibuat dalan sistem operasi Android versi 5.1.1 (Lollipop). Versi Android minimal untuk menjalankan aplikasi ini adalah versi 4.0 (Ice Cream Sandwich)

1. Perangkat keras yang digunakan

Spesifikasi perangkat keras yang digunakan dalam pembuatan aplikasi ini adalah sebagai berikut:
a) Laptop Processor Intel(R) Core(TM) i5- $2450 \mathrm{M} \mathrm{CPU} @ 2.50 \mathrm{GHz}$ (4 CPUs), $\sim 2.5 \mathrm{GHz}$
b) Random Access Memory (RAM) 6 GB.
c) HDD 750 GB
d) Intel VGA HD Graphics 30001632 MB.
e) Smartphone Android

2. Perangkat lunak yang digunakan

Spesifikasi perangkat lunak yang digunakan dalam pembuatan aplikasi ini adalah sebagai berikut:
a) Bahasa pemrograman: Java (Android), XML (Android)
b) Android Studio versi 1.5.1
c) Android Software Development Kit (SDK) Tools versi 25.1 .6
d) Java Development Kit (JDK) versi 864 bit
e) SQLite Manager versi 0.8.3.1
f) Balsamiq Mockups 3
g) Astah Professional

\section{Perancangan Sistem}

Perancangan perangkat lunak ini adalah perancangan program aplikasi yang akan dibuat untuk menampilkan Menu Daftar Lagu, Kuis, dan Tentangg dalam pemograman mobile device dengan menggunakan sistem operasi android.

Dalam perancangan aplikasi ini dilakukan dengan cara pemodelan yaitu use case diagram, activity diagram dan class diagram yang merupakan bagian dari UML.
Usecase Diagram

Use case diagram di gunakan untuk menjelaskan kegiatan yang dapat dilakukan oleh admin dan pengguna aplikasi . Sebuah use case hanya menjelaskan apa yang dilakukan oleh actor dan sistem. Adapun pada aplikasi ini, use case diagram terlihat pada gambar $\mathbf{2}$ dibawah ini.

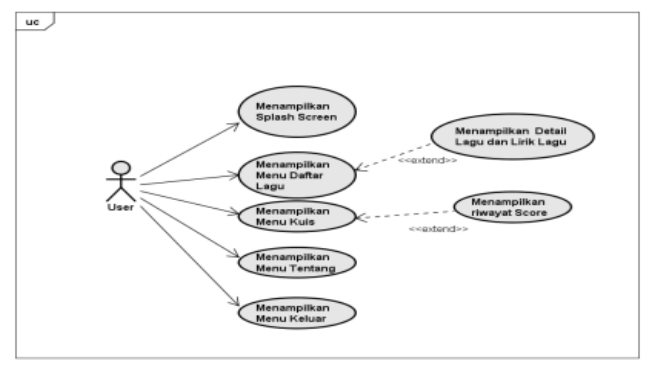

Gambar 2. Use Case Diagram Aplikasi

\section{Activity Diagram}

Activity Diagram digunakan untuk menggambarkan aliran dari suatu aktivitas ke aktivitas lainnya dalam sebuah aplikasi. Aplikasi ini, mengunakan Activity Diagram untuk menggambarkan aliran aktivitas sebuah interaksi antara user terhadap aplikasi.

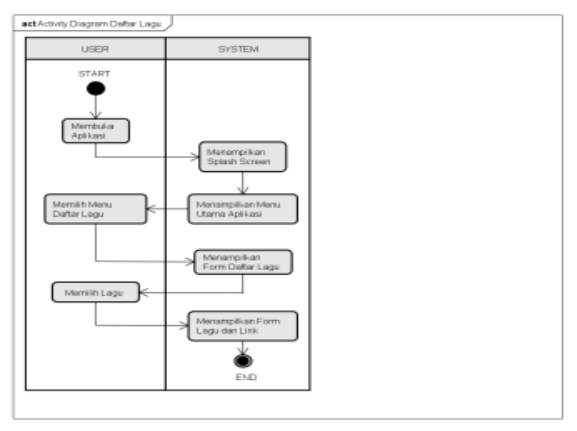

Gambar 3. Activity diagram daftar lagu

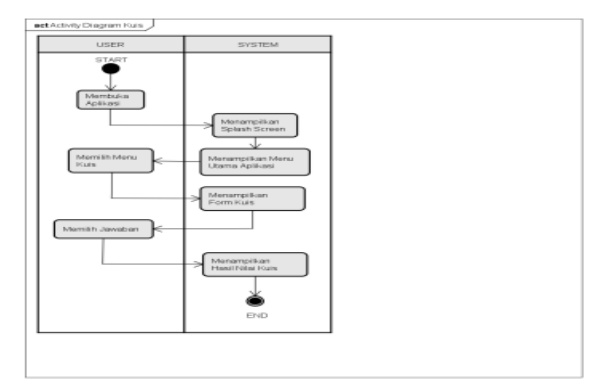

Gambar 3. Activity diagram kuis 


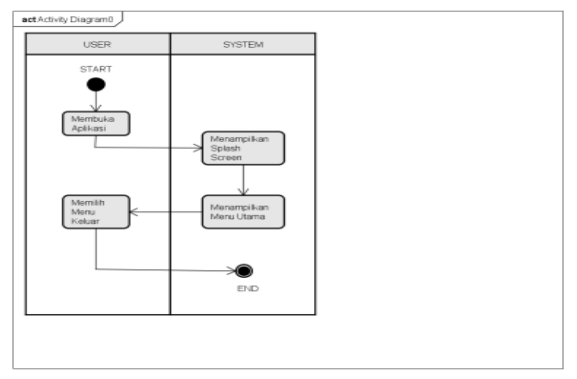

Gambar 5. Activity diagram tentang

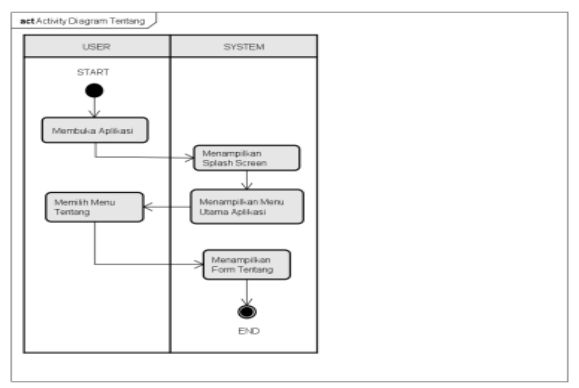

Gambar 6. Activity diagram logout

\section{Class Diagram}

Class diagram menggambarkan struktur dan deskripsi class beserta hubungan satu sama lain. Untuk lebih jelas dapat dilihat pada gambar 7 dibawah ini:

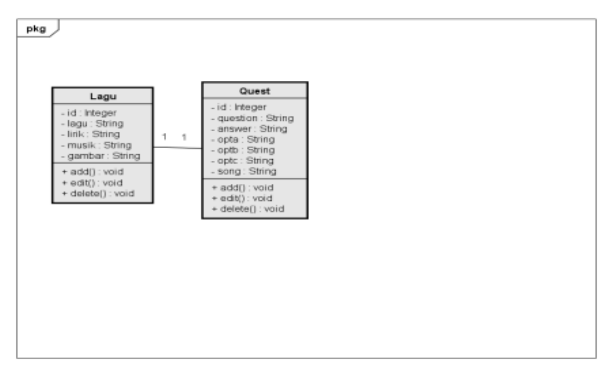

Gambar 7. Class diagram

\section{Perancangan Antarmuka Pengguna (User} Interface)

Rancangan antar muka merupakan tahap akhir dari bagian perancangan. Pada bagian ini dirancang tampilan yang bersinggungan langsung dengan pengguna. Pada bagian ini juga dapat terlihat sketsa atau gambaran secara utuh apa yang akan dikembangkan.

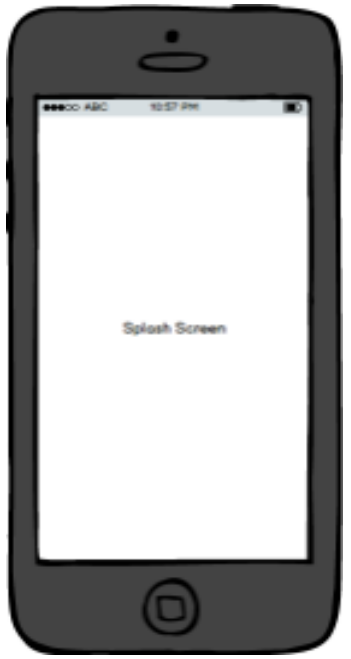

Gambar 4. User interface splash screen

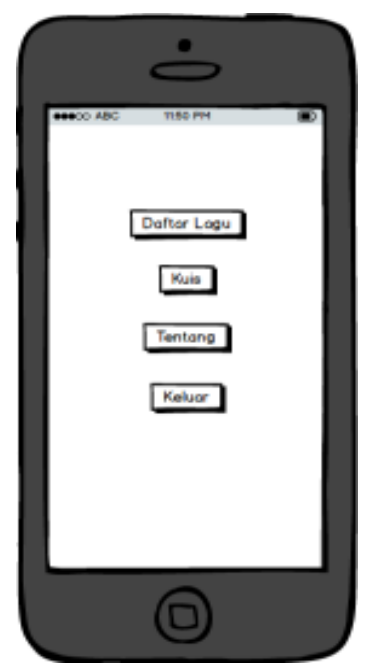

Gambar 5. User interface menu utama

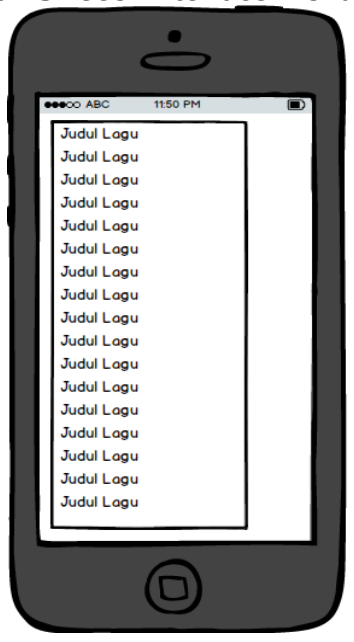

Gambar 6. User interface dari menu daftar lagu 


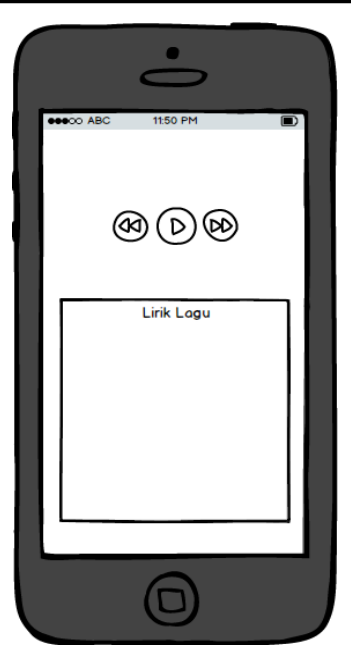

Gambar 7. User interface form detail lagu dan lirik lagu

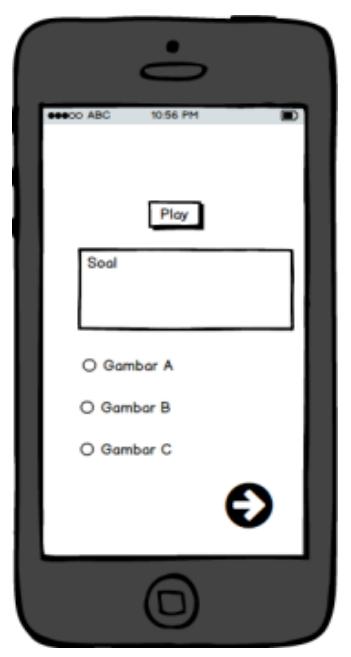

Gambar 8. User interface menu kuis

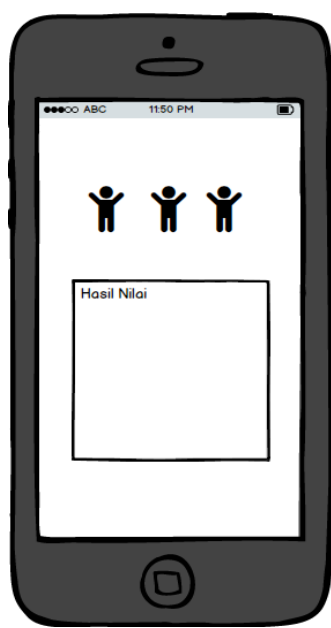

Gambar 9. User interface form score

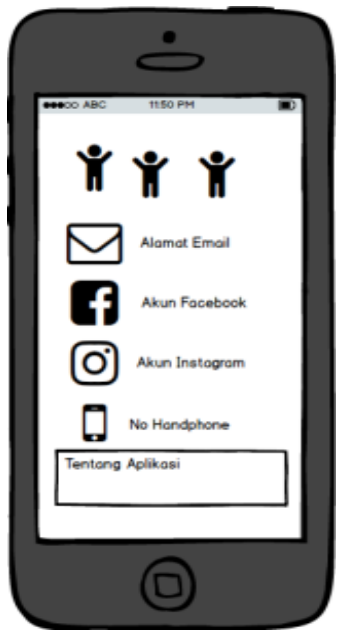

Gambar 10. User interface menu tentang

\section{Implementasi dan pengujian}

Implementasi antarmuka merupakan hasil dari perancangan antarmuka yang sebelumnya sudah dilakukan pada tahap perancangan.

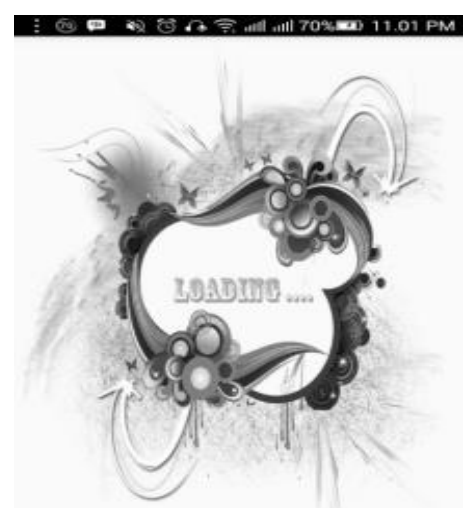

Gambar 15. Tampilan splash screen

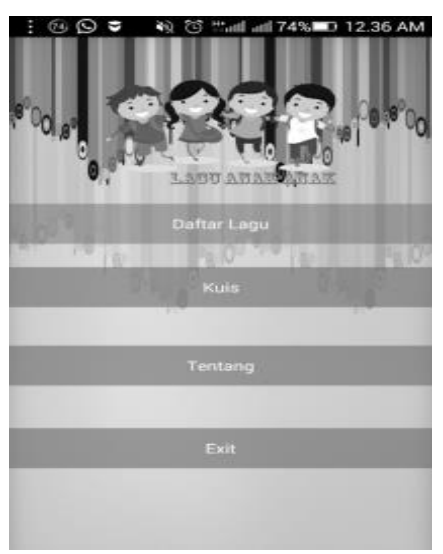

Gambar 16. Tampilan form menu utama 


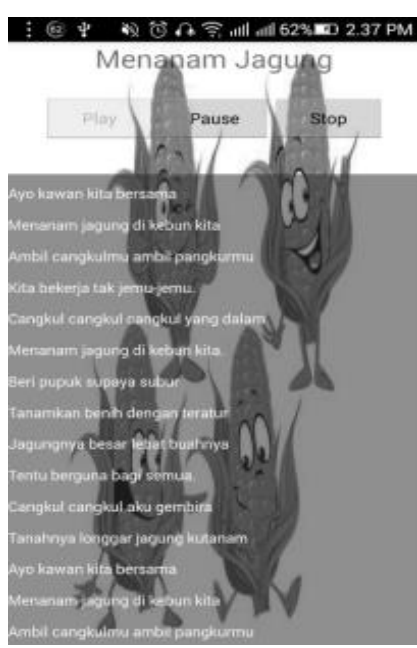

Gambar 17. Tampilan daftar lagu

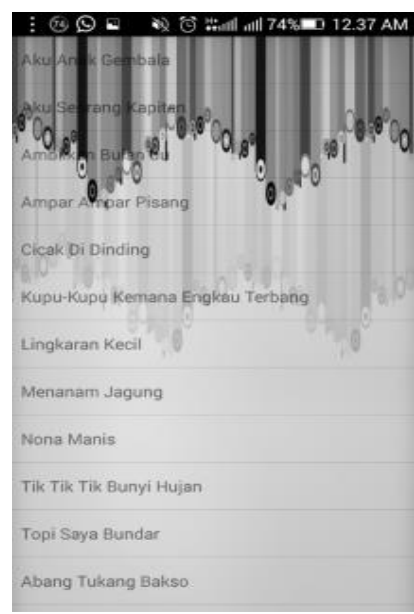

Gambar 18. Tampilan detail menu daftar lagu

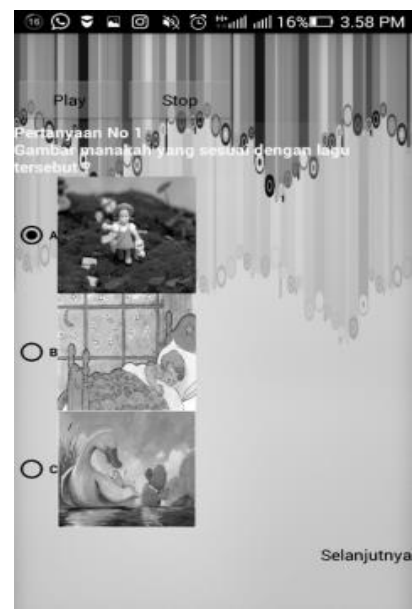

Gambar 19. Tampilan form kuis

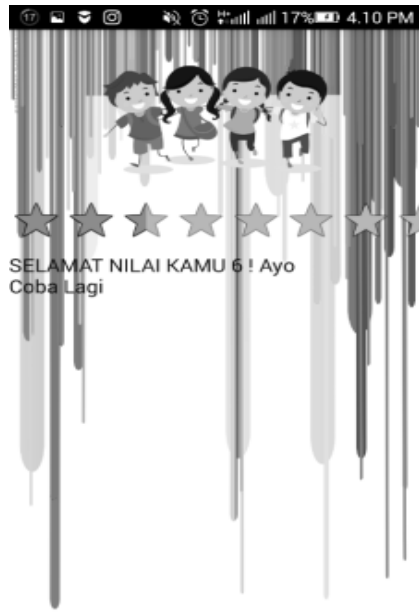

Gambar 20. Tampilan form score

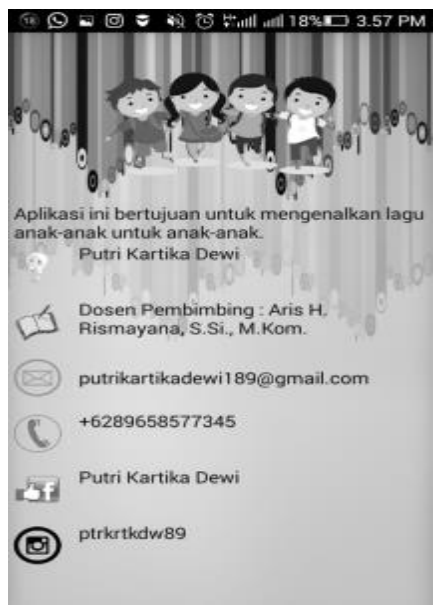

Gambar 21. Tampilan form tentang

\section{KESIMPULAN DAN SARAN Kesimpulan}

Kesimpulan yang dapat di ambil dari penelitian ini yang berjudul ini adalah sebagai berikut:

a) Aplikasi yang dibuat ini dapat dijadikan media pembelajaran yang menarik dan mudah dalam mempelajari dan memahami lagu anak-anak.

b) Dengan adanya menu Kuis, aplikasi ini dapat user gunakan untuk melatih sejauh mana kemampuanya untuk mengetahui, menghapal dan memahami lagu anak-anak, latihan soal ini berisi 15 soal yang jika jawaban benar semua maka akan muncul nilai sempurna.

c) Tampilan aplikasi menarik bagi kalangan anak-anak.

\section{Saran}

Saran untuk pengembangan Aplikasi Pengenalan Lagu Anak-Anak Berbasis Mobile ini agar lebih baik yaitu : 
a) Penambahan animasi / gambar bergerak agar aplikasi ini lebih menarik.

b) Aplikasi yang telah dibangun hanya menampilkan 20 lagu anak-anak, oleh karena itu untuk kedepannya diberikan penambahan jumlah lagu.

c) Penambahan fitur reset untuk soal latihan ketika user telah selesai mengerjakan soal latihan agar user dapat melihat perbandingan score terbaru dengan score yang di dapat dengan score yang di dapat sebelumnya.

\section{DAFTAR PUSTAKA}

Ananda, Y.(2015) Manfaat Lagu Anak-Anak.

Andy, (2013). Perancangan Aplikasi Penilaian Pekembangan Bahasa Anak Berbasis Android.

Ardhana, Y. K. (2013). Pemograman PHP Codeigniter BLACKBOX. (Yosepmurya, Ed.). Jasakom. Retrieved from www.tokomahal.com .

Ayuliana. (2009). Teknik Pengujian Perangkat Lunak, 1-6.

Developer.android.com. (2016a). Android Studio Overview. Retrieved January 5, 2016, from http://developer.android.com/tools/studio/inde x.html

Feri Djuandi. (2011). Menggunakan Database di Android.

Ferliana,M. (2014) Pemanfaatan Gadget Untuk Anak Usia Dini

Gousander, V. (2014). White-box testing \& Blackbox testing. Retrieved December 26, 2014, from http://goo.gl/WDpyRh

Jogiyanto, H. (2005). Analisis dan Desain Sistem Informasi, Edisi III. Yogyakarta: Andi.

Kamus Besar Bahasa Indonesia.

Karsono, (2014). Pengaruh Teks Lagu AnakAnak Terhadap Perilaku Prososial Anak TK.

Melorose, J., Perroy, R., \& Careas, S.(2015). Pengembangan Lagu Untuk Anak.

Mutiara, A. B. (2015). Testing implementasi website rekam medis elektronik opeltgunasys dengan metode acceptance testing, 8 (Kommit 2014), 1-7.

Nazruddin Safaat H. (2013). Aplikasi Berbasis Android.

Nugroho, A. (2005). Rational Rose untuk Pemodelan Berorientasi Objek.

Rina Wulandari, (2010). Pengembangan Lagu Untuk Anak 4-6 Tahun

Romeo. (2003). Testing dan Implementasi Sistem, Edisi Pertama. Surabaya: STIKOM.

Rouf, A. (2012). Pengujian perangkat lunak dengan menggunakan metode white box dan black box. 1-7.

Sugiarti, Y. (2013). Analisis \& Perancangan UML (Unified Modeling Languange) Generated VB.6. Graha IImu.

Utomo, E. P. (2012). From Newbie to Advanced. Andi Offset.

Yudistira, Y. (2011). Membuat Aplikasi Iphone, Android dan Blackberry itu Gampang. (A. Wahadyo, Ed.). Jakarta: Mediakita. 